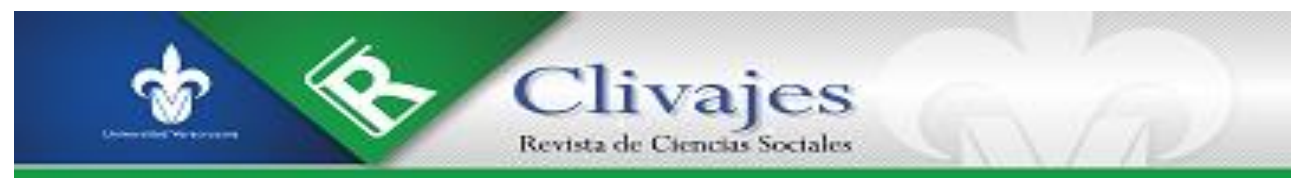

Yadira Romero López

LA VIOLENCIA EN LOS MÁRGENES. UNA MAESTRA Y UN SOCIÓLOGO EN EL CONURBANO BONAERENSE

Clivajes. Revista de Ciencias Sociales. Año V, número 10, julio diciembre 2018, pp. 133-138.

http://clivajes.uv.mx/index.php/Clivajes/article/view/2554/4436

Instituto de Investigaciones Histórico-Sociales, Universidad Veracruzana

Clivajes. Revista de Ciencias Sociales/ISSN: 2395-9495/IIH-S, UV/Xalapa, Veracruz, México.

Recibido: $13-11-2017$

Aceptado: $15 / 02 / 2018$

Publicación: 08/12/2018

Clivajes. Revista de Ciencias Sociales (ISSN: 2395-9495), Año V, Núm. 10, julio-diciembre, 2018 


\section{LA VIOLENCIA EN LOS MÁRGENES. UNA MAESTRA Y UN SOCIÓLOGO EN EL} CONURBANO BONAERENSE

\author{
Yadira Romero López \\ Estudiante de Doctorado \\ IIH-S, Universidad Veracruzana
}

Desde el título, el libro de Javier Auyero y María Fernanda Berti ${ }^{1}$ ofrece una doble mirada: un análisis sociológico de las dinámicas de violencia que viven los habitantes de un barrio marginado y un acercamiento pedagógico ${ }^{2}$ a las vivencias de los estudiantes del mismo barrio, cuya trama biográfica destaca significativamente

\footnotetext{
${ }^{1}$ Javier Auyero es hijo de uno de los líderes de la Democracia Cristiana en Argentina y referente de la centroizquierda política. Se desempeña como profesor de Sociología en la Universidad de Texas, en Austin, desde 1997. Fue discípulo del historiador y sociólogo Charles Tilly. Se doctoró en The New School for Social Research. Entre sus líneas de investigación se cuentan la etnografía política, la pobreza urbana, la acción colectiva, los estudios latinoamericanos y la teoría social y cultural. Ha escrito $L a$ zona gris. Violencia colectiva y política partidaria en la Argentina contemporánea; Inflamable. Un estudio del sufrimiento ambiental, coautoría de Débora Swistun, y Patients of the State, publicado en Estados Unidos por Duke University Press. Fernanda Berti obtuvo su título de Maestría en el Instituto Superior de Formación Docente de Banfield, en la provincia de Buenos Aires. Desde 2005 ejerce como docente de escuela primaria.

${ }^{2} \mathrm{Si}$ bien la obra no explicita un análisis con fines pedagógicos, en el acercamiento de Berti a las experiencias de los estudiantes se advierte ese filtro disciplinario, producto del posicionamiento de la autora como maestra frente a grupo. Esto se puede observar en cuestionamientos sobre el entorno escolar y el ambiente áulico, los cuales cobran importancia para Berti, que parte de tal ambiente para la reflexión conjunta con Auyero, y que ambos logran plasmar en La violencia en los márgenes.
}

en sus experiencias escolares, algunas de las cuales narra para acercarse a la especificidad de Arquitecto Tucci, como parte del área conurbana de Buenos Aires, Argentina, durante los años de 2009 a 2012. La documentación de experiencias narradas por alumnos de dos escuelas ubicadas en Arquiteto Tucci se llevó a cabo durante treinta meses en un diario de campo, pero la investigación se extendió por tres años.

El punto de partida para los autores fueron las discusiones públicas sobre la inseguridad en Argentina, teniendo como protagonistas a los sectores medios y medio-altos de la estructura social, los cuales dominan el discurso sobre la violencia urbana bajo el supuesto de que son quienes más la sufren. Para Auyero y Berti esto no es así; por lo contrario, desde su perspectiva, aun cuando el discurso les pertenece a otros, los habitantes de los márgenes urbanos son quienes viven a diario la inseguridad. De tal manera, la experiencia de la violencia interpersonal resulta negada, indecible y traumática, de ahí que el libro aborde el "trauma colectivo creado por la constante e implacable violencia interpersonal que se vive en un barrio marginalizado". Su propósito: hacer visibles y debatir las percepciones y vivencias respecto de la multiplicidad de violencias, sus usos y sus formas.

$\mathrm{Si}$ bien los alcances de la obra pueden determinarse mediante la lectura, los límites son más claros cuando los 
autores especifican algunas de las interrogantes que no consiguieron responder; por ejemplo, “¿Cuáles son los orígenes de tantas violencias? ¿Qué tipo de efectos colectivos e individuales generan a mediano y largo plazo? ¿Funcionan las violencias aquí expuestas como formas de control político y subordinación de los pobres por medio del terror? ¿Cómo? ¿Por qué?" (Auyero y Berti, 2013:8).

En el primer capítulo, "A la vera del Riachuelo: Arquitecto Tucci", los autores hacen una descripción contextual sobre dónde, cuándo y cómo se realiza la investigación, detallan, específicamente, la ubicación geográfica de Arquitecto Tucci, al sur del conurbado bonaerense, junto a la ribera de un riachuelo contaminado por desechos industriales. En ese territorio, se sobreponen tres distintas formas urbanas (barrios obreros, asentamientos y villas). Algunos terrenos recientes fueron tomados de áreas propensas a inundaciones. Se puede observar ahí la ausencia de infraestructura básica, aunada a la presencia de criminalidad y adicción a las drogas. Sin embargo, no se puede afirmar un abandono total del Estado, ya que existen establecimientos educativos y un hospital público, además de la operación de varios planes de asistencia social.

En un sentido más económico, las principales fuentes de ingresos en la zona son actividades como la albañilería, el reciclaje de basura, el servicio doméstico y una feria informal llamada "La Salada". Esta última se ha considerado un emblema mundial de la producción y falsificación de mercadería de marca. La significatividad de este espacio reside no sólo en la intensa relación económica y laboral establecida entre la población de Tucci y La Salada, que incluye altos niveles de explotación y trabajo infantil, sino también por la violencia interpersonal que acompaña las operaciones del mercado informal

En el segundo capítulo, "Entre balas e nacido" [sic], los autores amplían el contexto en el que se identifica la violencia interpersonal y mencionan nuevas formas de violencia, que tienen lugar en territorios de relegación urbana (comunas, favelas, poblaciones, cantegriles, villas) y afecta a las poblaciones más desposeídas de manera desproporcionada; particularmente, a adolescentes y jóvenes, tanto en su papel de víctimas como en su rol de perpetradores, lo cual indica una distribución desigual de la violencia. En este segundo capítulo se narran experiencias de "violencia callejera", sexual y doméstica vividas por los chicos que estudiaban en las escuelas participantes en la investigación, cuyas percepciones se ilustraron a través de los dibujos que realizaron. Parte importante de este capítulo abarca la clasificación de los diferentes usos de la violencia en barrios como Arquitecto Tucci; usos que van desde los más evidentes, como las represalias o intercambios recíprocos de violencia; los que se utilizan para avanzar sobre un territorio o protegerlo; las 
agresiones físicas para disciplinar a los hijos; agresiones a las que se recurre para autodefenderse; las que se despliegan con el fin de obtener recursos económicos, drogas o alcohol; las que se adquiere y mantienen un dominio sobre la pareja, hasta aquellas con las cuales se busca el reconocimiento.

En el capítulo 3, "Cadenas de violencia”, los autores centran su atención en casos que ejemplifican las conexiones entre eventos y personajes, así como en las formas, los usos y las experiencias de violencia latentes en un territorio marcado por la pobreza y otras condiciones. Afirman que ni los disparos de arma y enfrentamientos en las calles, ni los intentos de violación o las peleas al interior de una casa son fenómenos discretos, sino hechos intrínsecamente asociados. Se trata de diferentes formas de violencia cuya concatenación forma una red que enlaza y a la vez disuelve las líneas entre la calle y el hogar, las esferas pública y doméstica, de tal forma que mientras la violencia perpetrada en público puede actuar como conducto de socialización, en el ámbito privado también se sientan las bases para la violencia pública y viceversa.

En "El Estado en los márgenes", capítulo 4 del libro que nos ocupa, Auyero y Berti analizan etnográficamente las formas en que el Estado se hace presente en el territorio. Los autores se preguntan ¿cómo, cuándo y con qué efectos interviene el Estado en las disputas de los más pobres en los lugares donde viven? Argumentan, para responderla, que la aplicación de la ley en espacios urbanos marginales, como Arquitecto Tucci, es simultáneamente intermitente, selectiva $\mathrm{y}$ contradictoria. Afirman que no se trata de una baja o nula presencia del Estado, sino de una colusión entre el poder de la policía y la criminalidad, análoga a la descrita por Desmond Arias (en el caso de las favelas de Río de Janeiro), e insisten en que no es un fracaso del Estado, sino una activa constelación de intereses cuyo resultado es la promoción de la violencia.

Cabe resaltar que los autores no se concentran en los orígenes, en los efectos de la violencia ni en su posible uso político. El centro de atención de los autores resulta relevante porque analiza las intersecciones y la propagación de ciertas formas de violencia. Su argumento es que, en buena parte, la violencia prevaleciente en los barrios pobres sigue la lógica de la "ley del talión" en respuesta a una ofensa previa. Sin embargo, tanto dentro como fuera del hogar, en la casa y en la calle ocurren otras formas de agresión física que trascienden el intercambio interpersonal y adquieren una forma menos demarcada, más expansiva. Se esparce y se asemeja, en algunas ocasiones, a una cadena que relaciona distintos tipos de daño físico y, en otras, a un derrame que contamina todo el tejido comunitario; de ahí que el libro enfatice las concatenaciones y las interacciones violentas, uno de los campos más 
recurrentes en los desarrollos teóricos utilizados para el estudio de la violencia.

Para el análisis de dicha problemática, los autores presentan, a la vez, las categorías "cadena" y "derrame", como imagen abarcadora, para dar cuenta de las formas y los usos de la violencia en los márgenes, y desarrollan también una contextualización en dos vías complementarias. Ubican cada episodio violento percibido en su contexto estructural más amplio, pero también en su contexto situacional más específico, para aprehender la persistencia de la violencia cotidiana y, al mismo tiempo, entender y explicar "la enorme cantidad de formas de brutalidad interpersonal" que se registran en el territorio estudiado, y las maneras en que se conectan unas con otras. Para ello reconstruyen las perspectivas de "víctimas", "testigos" y "victimarios", con la aclaración de que los episodios reconstruidos pueden aparecer como ejercicios de crueldad, a simple vista, pero que, tras una atenta observación, pueden develar motivos emocionales como la frustración o la impotencia de las familias, cuyo recurso para hacer frente a la violencia es la violencia misma.

Auyero y Berti sustentan La violencia en los márgenes... en una investigación que abreva de diversas fuentes etnográficas y documentales. Recurrieron, por ejemplo, a directivos y médicos de hospitales y salas de salud locales, así como a comedores comunitarios, para realizar entrevistas en profundidad, obtener datos básicos de carácter estadístico sobre violencia interpersonal y criminalidad, además de usar fuentes secundarias sobre delitos en esa zona de estudio. Cada día, tomaron notas de campo después de trabajar con distintos grados educativos de escuelas locales, con los que utilizaron la elaboración de dibujos y un taller de fotografía como técnicas para recabar información.

La investigación se caracteriza, metodológicamente, por emprender una reconstrucción etnográfica que combina la narración de historias con la recuperación de eventos específicos, a través de testimonios sobre la violencia interpersonal que vivieron, directa o indirectamente, los actores: estudiantes, personal de instituciones de salud y vecinos, inmersos en los ámbitos más comunes del barrio. Para ello, Auyero y Berti aprovecharon sus conocimientos al respecto; la primera por trabajar como maestra en ese lugar, y el segundo por haber participado académica y políticamente en esa zona en momentos anteriores.

La escritura del libro tiene como elemento complementario la reproducción de fragmentos de canciones populares en los barrios y las "villas de emergencia", a partir de lo cual se percibe una intención narrativa y metodológica para ilustrar las dinámicas de violencia que forman parte de la vida cotidiana de la población de algunos barrios, entre ellos el que se estudió. Esta información $\mathrm{y}$ otros detalles pueden 
encontrarse a lo largo de la obra, y específicamente en el Apéndice metodológico.

Resta mencionar algunos detalles importantes; en particular, desde el inicio del libro se advierte una preocupación/ocupación de los autores por evitar una lectura equivocada, para lo cual brindan herramientas conceptuales y recomendaciones básicas, a manera de invitación, para que los lectores hagan una lectura justa del planteamiento y la presentación de las narraciones experienciales de episodios violentos. Esto es evidente en la insistencia con la cual especifican las decisiones tomadas para la presentación de tales testimonios y episodios violentos. Este acompañamiento cauto de los autores a los lectores, si bien se agradece y se entiende en un contexto social y mediático actualmente plagado de excesos gráficos, descriptivos de violencia explícita, también llega a resultar reiterativo. No obstante, el detalle queda en segundo plano, si se tiene en cuenta la sensibilidad de los autores para el tratamiento del tema y su respeto hacia los participantes de la investigación, pues advierten que, aun con las mejores intenciones, académicos y periodistas pueden sumarse a la "guerra simbólica" contra los que viven en riesgo permanente en los márgenes urbanos. Aquí los autores fijan su postura respecto de la política de representación de los grupos subalternos.
En relación con los resultados de la investigación, reportan escasa agresión física interpersonal al interior de las escuelas, lo cual es digno de resaltarse, ya que coincide con otros estudios nacionales y extranjeros. Por último, cabe destacar que, como bien señalaron los autores en "El plan del libro", La violencia en los márgenes... no presenta un desarrollo muy elaborado en términos teóricos; su aportación es otra: dar visibilidad a las formas en las que se experimenta y se piensa "la violencia" desde el punto de vista de quienes la viven, es decir, escuchar y dar cuerpo a las voces de quienes la perpetran y la reciben, y no sólo de los otros que la perciben y le temen. Así, el manejo categorial que presentan con los conceptos "cadena de violencias" y "derrame" resultan en una propuesta interesante y útil, cuya aparente "simplicidad" invita a su relectura y aplicación en el ámbito investigativo de las violencias.

Auyero, J. y Berti, M. F. (2013). La violencia en los márgenes. Una maestra y un sociólogo en el conurbano bonaerense. Buenos Aires, Argentina: Katz. 174 pp. 